\title{
Interply Layer Degradation Effects on Composite Structural Response
}

Christos C. Chamis

Lewis Research Center

Cleveland, Ohio

and

George C. Williams

The University of Arizona

Tucson, Arizona

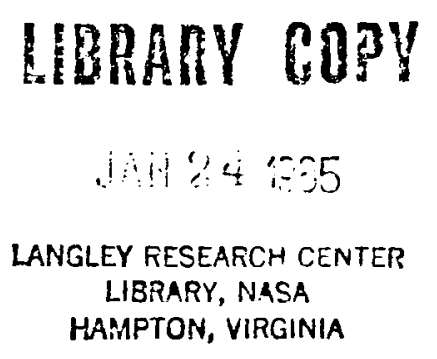

Prepared for the

Twenty-fifth Structures, Structural Dynamics and Materials Conference cosponsored by the AIAA, ASME, ASCE, and AHS

Palm Springs, California, May 14-16, 1984 
:

• 


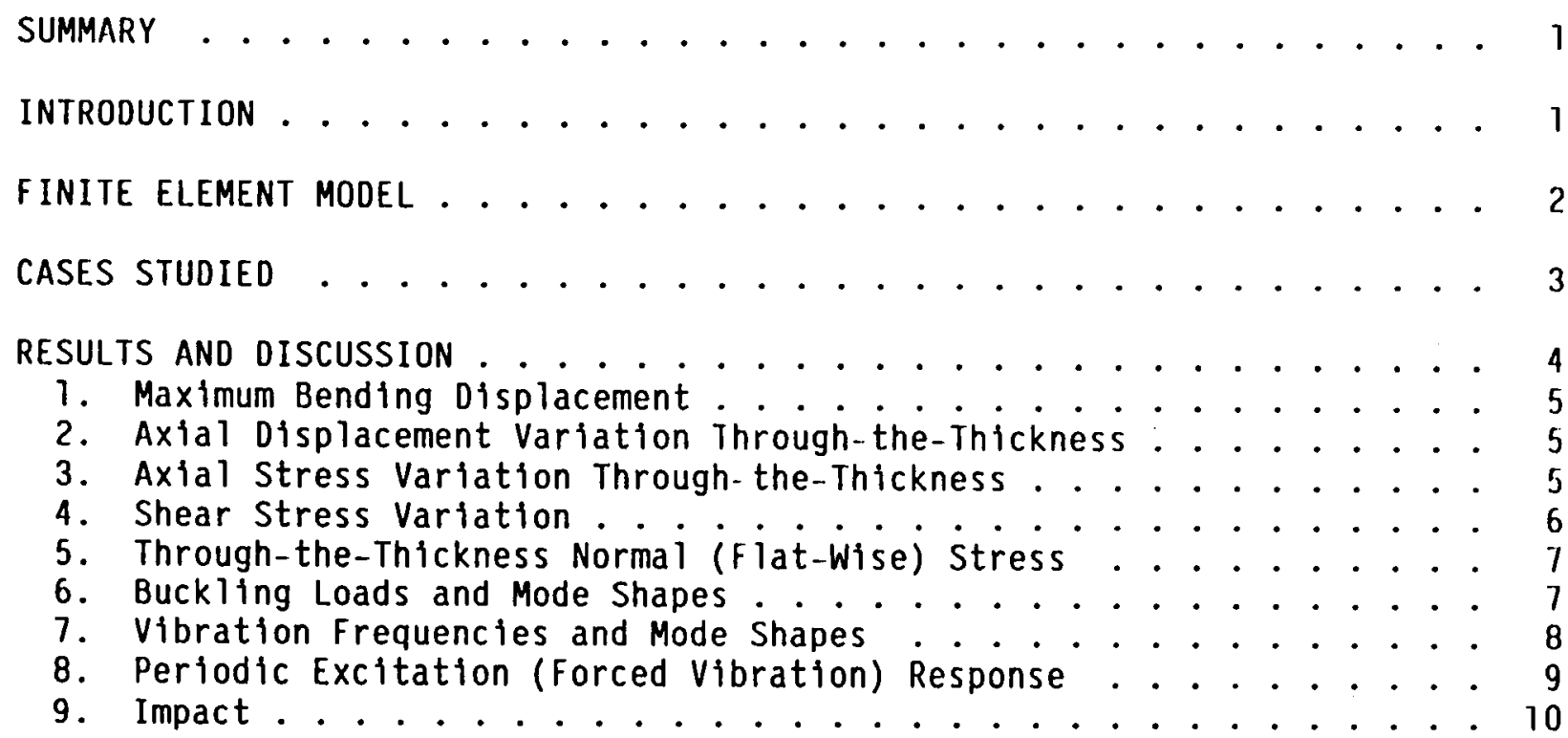

SUMMARY OF RESULTS .......................... . . . 10 
. 


\section{INTERPLY LAYER DEGRADATION EFFECTS ON COMPOSITE}

STRUCTURAL RESPONSE

by

Christos C. Chamis 1

NASA Lewis Research Center

Cleveland, Ohio

and

George C. Williams2

The University of Arizona

Tuscon, Arizona

\section{SUMMARY}

Recent research activities at NASA Lewis Research Center to computationally evaluate the effects of interply layer progressive weakening (degradation) on the structural response of a composite beam are summarized. The structural responses of interest include: (1) bending, (2) buckling, (3) free vibrations, (4) periodic excitation, and (5) impact. Finite element analys is was used for the computational evaluations. The interply layer degradation effects on the various structural responses were determined and assessed as a function of the interply layer modulus varying from 1 million psi down to 1000 psi and even lower for some limiting cases. The results obtained show that the interply layer degradation has generally negligible effect on composite structural response and, therefore, structural integrity, unless the interply layer modulus degrades to about 10000 psi or less.

\section{INTRODUCTION}

Fiber reinforced composites are optimally utilized when they are designed to resist and/or transfer in-plane loads. Plies made from aligned fibers are oriented in different directions to resist these in-plane loads either in tension or compression. The different plies are held together by the interply (interlaminar) layers (matrix) which provide the composite with the structural integrity required to resist in-plane loads. Any degradation of the interply layers can affect the composite structural integrity. As a result, interply layer degradation effects on fiber composite structural integrity are receiving considerable attention. Interply degradation is generally in the form of delaminations or progressive weakening of the interply layer. In either case, the composite angleplied laminate will most likely behave like a stack of individual layers (beams) instead of a composite. Compared to the undelaminated composite, individual delaminated layer behavior dramatically degrades out-of-plane structural response such as flexural deflections (bending), buckling, vibration and impact. For example (1) the flexural deflection increases as the square of the number of delaminated layers, (2) the flexural stress increases linearly with the number of delaminated layers, (3) the buckling load decreases as the square of the number of layers, and (4) the frequency decreases linearly with the number of delaminated layers.

\footnotetext{
Aerospace Structures and Composites Engineer; AIAA Associate Fellow.
}

2Ph.D. Candidate, Department of Civil Engineering. 
The present paper summarizes some recent research at Lewis. The objective of which was to computationally determine and assess the effects of interply layer progressive weakening (degradation) on the structural response of a composite beam. The structural response of interest includes: (1) bending, (2) buckling, (3) free vibrations, (4) periodic excitation, and (5) impact. Finite element analysis was used for the computational method. The interpiy layer degradation effects on the various structural responses were determined and assessed as a function of the interply layer modulus, varying from one million psi down to 1000 psi and even lower for some limiting cases. The finite element model used, the analysis, the cases studied and attendant justifications, and the results obtained are described and discussed in considerable deta11. The results obtained are presented graphicaliy to show the interply layer degradation effects on composite structural integrity for the range of interply layer (matrix) modulus considered.

\section{FINITE ELEMENT MODEL}

The geometry and finite element idealization of the beam used for this investigation are depicted in figure 1 together with boundary conditions and material properties. The aspect ratio of the beam is about 10 to 1 ( 40 in. length, 4.3 in. depth). This ratio was selected in order to accentuate through-the-thickness shear contributions. The beam width is $0.1 \mathrm{in}$.

The beam is modeled using a uniform mesh consisting of 12 nodes throughthe-thickness and 41 nodes along the span for a total of 492 nodes. The uniform mesh is considered to be adequate for this study since the focus was on beam behavior rather than local stress concentrations that exist in the vicinity of the applied loads and near the end supports. Each node had two in-plane degrees-of-freedom (DOF) $u$ and $v$ as shown in figure 1 . Twelve DOF through-the-thickness essentially permit the axial displacement $(u)$ to be described from a constant up to an eleven degree polynomial. This mesh density was selected mainly to permit each ply to behave like an individual simple beam (three nodes through its thickness) and to allow each interply layer to deform in simple shear (two nodes through its thickness).

The beam was modeled using eleven quadrilateral elements through-thethickness and forty quadrilateral elements along the span. Two elements were used to model each ply thickness and one element to model each interply layer. The two elements for each ply allow the ply to approximately deform like a simple beam. The one element for each interpiy layer permits the interply layer to predominantly deform in simple shear. The aspect ratio of the ply elements is 2 to 7 which is a reasonable approximation for individual ply bending. The aspect ratio of the intraply elements is 10 to 1 which is also a reasonable approximation for simple shear.

The boundary conditions were selected to simulate a beam with simple support at one end $(x=y=0)$ and sliding support at the other $(x=\ell, y=0)$. Symmetry conditions, normally prescribed at the beam center, were not used. This was done intentionally in order to eliminate single-point restrained effects near the beam center as much as possible. 
The material properties used for the ply were typical of those for AS graphite fiber/epoxy matrix (AS/E) composite (fig. 1). The modulus for the interply layer varied from about 1000 psi up to one million psi. The variations in the interply layer modulus were selected to simulate interply layer progressive material degradations which could be caused, for example, by (1) environmental effects (moisture, temperature), (2) flexible (toughened) matrix, (3) separate adhesive layer, (4) partial delamination, and (5) intermittent disbonds.

The computations were performed using the COSMIC NASTRAN computer code, a general purpose structural analys is finite element computer program.

\section{CASES STUDIED}

The effects of progressive interply layer degradation on beam behavior were studied by considering the following cases: (1) maximum bending displacement ( $v$, fig. 1); (2) through-the-thickness variation of the axtal dis. placement (u, fig. 1); (3) through-the-thickness axial stress variation; (4) through-the-thickness interlaminar shear stress variation; (5) throughthe-thickness normal (flat-wise) stress; (6) buckling loads and mode shapes; (7) free vibration frequencies and mode shapes; (8) periodic excitation (forced vibration) response with and without damping; and (9) impact. These cases were selected to evaluate (assess) and identify specific cause-and-effect relationships on the beam structural response as summarized subsequently.

(1) Maximum bending displacement - This case was selected to quantify the range of interply layer degradation causing excessively large beam bending displacements. Large beam bending displacements are detrimental to overall structural integrity. However, these displacements are essential for absorbing impact energy and for containing impacting-fragments.

(2) Axial displacement variation through-the-thickness - This case was selected to identify the level of interply layer degradation below which each ply in the beam starts behaving like a simple beam. At this level of degradation, the beam ceases to behave like a composite and behaves like a stack of individual layers. Again, behavior of this type severely penalizes overall structural integrity but significantly enhances fracture toughness, damage tolerance and impact containment.

(3) Axial stress variation through-the-thickness - This case was selected in order to (7) identify the level of interply layer degradation below which the simple beam assumption (linear axial stress variation through-thethickness) is violated, and (2) determine the magnitude of bending stress in each ply when the plies started behaving like individual layers. Both of these are significant to determine interply layer degradation effects on fracture progression in the beam. For example, will the fracture be (1) catastrophic once the maximum-stressed ply fractures, or (2) progressive requiring increases in load to sequentially stress each individual ply to its fracture stress.

(4) Shear stress variation through-the-thickness - This case was primarlly selected to determine: (1) the level of interply layer degradation at which the parabolic shear stress variation through the thickness, predicted by simple beam theory, is violated; (2) the shear stress transfer from ply to 
interply layer (as represented by uniform displacement -- elements in parallel, or by uniform stress -- elements in series); and (3) the magnitude of the interply layer shear stress in order to identify possible interlaminar fracture.

(5) Flat-wise stress variation - This case was selected to determine the level of the interply layer degradation below which the stress in the interply layers become sufficlently large to induce possible local fractures and permit predominant local membrane action.

(6) Buckling loads and mode shapes - This case was selected (1) to assess the overali structural integrity of the beam with progressive interply layer degradation, and (2) to determine the degradation level below which the individual plies will buckle locally. The latter point is significant in assessing the onset and progression of delamination under compression fatigue.

(7) Free vibrations and mode shapes - This case was selected to determine the level of interply layer degradation which induces through-the-thickness (breathing-type) vibration modes. These modes are significant in assessing the structural integrity of the beam as well as the stress wave propagation in the beam and candidate sites for local fracture.

(8) Forced vibration or periodic excitation response - This case was selected to assess the interply layer degradation and damping effects on the bending displacement of the beam. These are significant in determining fatigue life of a composite with various interply layer characteristics, some of which were delineated in item (3) above.

(9) Impact - This case was selected in order to evaluate interply layer progressive degradation effects on the impact response of the beam. For example, this case makes it possible to identify degradation magnitudes which cause excessively large impact displacements which will, therefore, permit comparatively large amounts of impact energy to be absorbed.

As was previously mentioned, COSMIC NASTRAN was used for the computations. The CQUAD2 elements were used with MAT2 material cards to accommodate anisotropic properties. The composite material properties used for the plies are typical of a T300 graphite fiber/epoxy matrix unidirectional composite. The specified rigid formats used are as follows: RIGID FORMAT 1 for cases 1 through 5, RIGID FORMAT 5 for case 6, RIGID FORMAT 3 for case 7, RIGID FORMAT 8 for case 8 , and RIGID FORMAT 9 for case 9 . The numerical results obtained are presented and discussed in the next section.

\section{RESULTS AND DISCUSSION}

The computational results obtained for the various cases are presented in graphical form and discussed in the same order described in the previous section. The graphs represent the specific variable in each case as a function of the progressively degraded modulus of the interply layer and/or as a function of the through-the-beam thickness. 


\section{Maximum Bending Displacement}

The interply degradation effects on the maximum beam displacement (due to a 100 lb concentrated load at the center) are shown in figure 2. The center deflection increases very rapidly as the interply modulus degrades below about $50000 \mathrm{psi}$. This deflection is practically insensitive to interply layer modulf greater than about $100000 \mathrm{psi}$. Most of the structural epoxies have moduli of about $400000 \mathrm{psi}$ or greater. This indicates that substantial degradation in the interply layer must occur before the maximum bending displacement becomes excessively large.

Several remarks can be made relative to the conditions under which the interply layer modulus might degrade to 50000 psi or less. For example: the interply layer must be in a rubber-11ke state; (2) a structural epoxy must be used near its glass transition temperature to have such a low modulus; (3) the composite must be used at about $340^{\circ} \mathrm{F}$ with 2 percent moisture by weight, for example, to have such a low interply layer modulus; (4) all three interply layers must have a uniform porosity of about 90 percent by volume; or (5) a 11 three interply layers must have sustained extensive damage comparable to 90 percent porosity.

Two conclusions follow from the above discussion: (1) the interply layer must degrade substantially or be made from very "soft" material (having about 10 percent of the structural epoxy modulus) in order to significantly affect the maximum bending displacement; and (2) degradations of the interply layer which do not reduce its modulus below 100000 psi have negligible effect on the maximum bending displacement.

\section{Axial Displacement Variation Through-the-Thickness}

The interply degradation effects on the axial displacement due to a 100 pound load at the center are shown in figure 3 . The displacement variation through-the-thickness is plotted for four different values of the interply layer modulus.

The observations/conclusions to be made from the results in figure 3 are: (1) the plies in a composite beam start behaving like individual beams (layers) when the interply layer modulus degrades below 100000 psi; (2) the interply layer undergoes substantial deformation when the interply modulus degrades down to 10000 psi; (3) the plies behave like individual simple beams at relatively low values of the interply modulus (about 10000 psi); and (4) simple beam theory and/or laminate theory cannot be applied to the composite beam when the interply layer modulus degrades below 100000 psi since the assumption of plane sections remaining plane is violated.

\section{Axial Stress Variation}

The interply degradation effects on the axial stress due to $100 \mathrm{lb}$ load at the center are shown in figure 4 for four different values of the interply layer modulus. The circles in the graphs denote the center of the finite element at which the stress was computed. Recall that two finite elements are used for each ply and one for each interply (fig. 1). Straight line segments 
are drawn through the ply elements to represent the stress gradient through the ply. These straight line segments are connected to the point representing the interply stress.

For the homogeneous case, the stress varies linearly through-the-thickness and is approximately the same as predicted by simple beam theory, as would be expected from the axial displacement variations (fig. 3). The axial stress in the interplies is negligible for an interply layer modulus of 1 million psi as would be expected from simple beam theory. The stresses in the plies follow a straight line that is the same as that for the homogeneous case. The same is observed for the case where the interply layer modulus equals 100000 psi case except for the slight jump at the mid-plane.

Obviously, each ply behaves like an individual beam for the case where the interply layer modulus equals $10000 \mathrm{psi}$. The axial stress magnitudes in the plies are about 30 percent higher compared to the other cases while that in the interply is negligible. The discontinuity in the axial stress from plies to interply is about two times that of the case for $E$ equals 100000 psi. This implies relatively large shear strains in the interplies as well as in the plies at these locations. The straight line segments representing the stress variation in each ply are parallel. Also, the straight line drawn through the maximum stress points at the top and bottom of the beam passes through the mid-plane of the beam as would be expected since the moduli in tension and compression were assumed to be equal in the computations.

The conclusions from the results shown in figure 4 and attendant discussion are: (1) the plies in a composite beam behave like individual beams when the interply layer modulus degrades down to 10000 psi or about 0.05 percent of the ply modulus $\left(0.01 \times 10^{6} \mathrm{ps} i\right.$ versus $\left.20 \times 10^{6} \mathrm{ps} i\right)$; and (2) the assumptions inherent in simple beam theory and/or laminate theory remain valid when the interply layer modulus is 100000 psi or about 0.5 percent or greater of the ply modulus.

\section{Shear Stress Variation}

The interply degradation effects on the shear stress at the quarter and half spans are shown in figure 5 for four different values of interply modulus. The shear stress variation through-the-thickness at the quarter span is quadratic for the first three cases (homogeneous, E equals one million psi and $100000 \mathrm{psi}$ ). This is consistent with that predicted using simple beam theory. However, for the $E$ equals $10000 \mathrm{ps} i$ case, the shear stress is discontinuous across the interplies. The shear stresses in the plies are about 50 percent less than would be predicted by simple beam theory. Near mid span of the beam, the shear stress varies from zero at the bottom ply to the maximum value at the top ply (near the load point). At this location, the shear stress concentrates at the top ply as the interply degradation approaches the equivalent of a delaminated condition.

Two important observations follow from the results in figure 5 : (1) the shear stress is less than that predicted using simple beam theory when the interply modulus degrades down to about 10000 psi (about 0.05 percent of that in the plies); and (2) the shear stress is discontinuous through-the-beam thickness at this level of degradation. It can be concluded that the shear 
strain is continuous in composites with highly degraded interplies. This is in contrast to the continuous shear stress predicted by using simple beam theory. It indicates that a transition from shear stress continuity to shear strain continuity occurs as the interply degradation approaches delamination.

It is worth noting that shear strain continuity is consistent with large deflection theories based on small strains but large rotations. It is also worth noting that composites made with soft interply layers will undergo large bending displacements, will sustain large shear strains in the interply layers but with relatively low shear stresses, and could be designed to enhance im. pact resistance.

\section{Through-the-Thickness Normal (Flat-wise) Stress}

The interply degradation effects on the flat-wise stress for a section at quarter-span are shown in figure 6 for 8 different interply layer moduli. It is interesting to note that: (1) this stress is tensile for the major part of the thickness, when the interply modulus is greater than $50000 \mathrm{psi}$; (2) it remains tensile and its magnitude increases as the interply modulus degrades down to 50000 psi; (3) it transitions to compression in the upper part when the interply modulus degrades down to $10000 \mathrm{psi}$; and (4) it becomes compressive throughout as the interplies approaches delamination. It is also interesting to note that this stress remains continuous throughout the degradation range.

Three significant conclusions follow: (1) the flat wise stress does not depend on local stiffness; (2) the plies would remain in contact under com. pressive load even in the presence of delaminations; and (3) the flat-wise stress is relatively negligible except as the interply degradation approaches the equivalent of a delaminated condition. These conclusions are equally applicable when the center load is tensile but prior to any delamination.

\section{Buckling Loads and Mode Shapes}

The interply degradation effects on the buckling load of a composite beam are shown in figure 7 . The boundary conditions used to simulate a simply supported beam are depicted by the insert.

The buckling load: (1) decreases negligibly as the interply layer modulus degrades from $E$ equals 1 million psi to $E$ equals 0.5 million psi; (2) decreases mildly in the range $E$ equals 0.5 million psi to 0.2 million; and ( 3 ) decreased rapidiy as $E$ degrades below 0.2 million psi.

The corresponding buckling mode shapes are shown in figure 8 . No dis. cernible effects are noted in the buckling mode shapes through the interply degradation range. This implies that it requires relatively small (almost negligible) interply stiffness, to preserve unimodal (Euler-type) buckling shape of all the plies. Based on these results axial barreling and/or split. ting under axial compressive load appear highly unlikely. However, hot-wet environments will degrade buckling resistance since these environments decrease the interply layer modulus as well as that of the matrix in the plies. 
The important conclusions from the afore discussion are: (1) interply degradation has significant effects on the buckling load and, therefore, structural integrity of the composite as the interply modulus degrades below 0.4 million psi or about 0.2 percent of the ply modulus; and (2) relatively small interply stiffness and strength are required to preserve unimodal buckling of all the plies in the beam (that is prevent "barreling or splitting modes of buckling).

Vibration Frequencies and Mode Shapes

The interply degradation effects on the first four frequencies of a composite beam are summarized in figure 9 . The beam was supported only at the nodes shown in order to permit through-the-thickness vibration modes.

It can be seen that interply degradation has negligible effects on the first three frequencies when the interply layer modulus is greater than 0.2 million psi. The frequencies decrease rapidiy as the interply layer modulus decreases below: (1) 0.2 mitition psi for the mode 4 ; (2) 0.1 milition psi for modes 2 and 3 ; and (3) 0.05 million psi for mode 1 . Mode 4 is the most sensitive to interply degradation implying that higher modes may be even more sensitive since the motion of these higher modes becomes more localized. Note that the frequencies for these modes are not integer multiple of each other as would be anticipated from simple beam theory. The contributing factors will be discussed later.

The vibration mode shapes for mode 1 are shown in figure 10 . These mode shapes show unimodal shape of all the plies with increasing shearing and through-the-thickness motions near the beam ends as the interply layer modulus degrades. The mode shapes for mode 4 are shown in figure 11 . As can be seen, the beam undergoes considerable shearing and through-the-thickness motions at this mode for $E$ equals 0.1 and 0.01 million $p s i$ and becomes virtualiy a through-the-thickness mode for $E$ equals 1000 psi.

It is important to note that the mode shapes of mode 4 deviate considerably from the mode shapes that would be predicted using simple beam theory. This deviation occurs, in part, because of the following factors: (1) the flexural wave length of this mode becomes short relative to the beam thickness; (2) the low shear stiffness of the composite contributes to substantial shear deformations (about 35 percent of the bending deflection) in this aspect ratio of the beam (about 10 to 1); (3) the low shear stiffness of the interply layers permit coupled bending axial modes; and (4) the low interply stiffness and end support conditions permit through-the-thickness modes to occur earlier. These factors also cause the frequencies in figure 10 to deviate from being integer multiples of each other as was previously mentioned.

Another significant point to be noted in figure 11 is the mode shape for the case when $E$ equals $1000 \mathrm{psi}$. The bottom ply vibrates in a mode shape similar to the other three cases. However, the other three plies vibrate in the first mode which is similar to that of beams on relatively soft foundations.

Three conclusions follow from the afore discussion: (1) beams vibrate as a composite until the interply degradation approaches the equivalent of a delaminated condition; (2) the beam aspect ratio, the low shear stiffness of the 
composite and the degraded interply layer cause coupled bending-axial and through-the-thickness vibration modes which deviate of integer multiples from each other; and (3) through-the-thickness vibration modes appear as the flexural wave length approaches the beam thickness which occurs at relatively high vibration modes especially in typical composite laminates. The last conclusion has significant implications with respect to fatigue-induced propagation of interply delamination in laminates and adhesively bonded joints.

\section{Periodic Excitations (Forced Vibration) Response}

The interply degradation effects on the forced vibration response of the composite beam were evaluated by exciting the beam at the center with a sinus. oidal forcing function of $100 \mathrm{lb}$ amplitude and near resonance to the four vi. bration modes described previously. Different types of damping were considered in the evaluation, namely, no damping, uniform damping and two types of inter. ply damping (fig. 12). The first type of interply damping is assumed to vary only with modulus while the second with modulus and shear stress.

The interply degradation effects on the maximum displacement are shown in figure 13 for the four vibration modes described previously and for the dif. ferent types of damping. The interesting points to be noted are: (1) the higher mode excitations have relatively low amplitudes compared to the first mode; (2) interply damping is more effective than uniform damping; (3) both types of interply damping have practically the same effect on the displacement; (4) damping has negligible effects on displacement when the interply modulus is greater than 0.1 million psi for the first mode and negligible effect throughout the modulus range for the other three modes; and (5) the amplitude of the first mode increases rapidly as the interply modulus degrades below 0.1 million psi in all cases with damping.

The displacement for the first mode response is shown in figure 11 for three values of the interply layer modulus with no damping and with intraply damping varying with modulus and with shear stress. Corresponding results for the second, third and fourth modes are respectively shown in figures 15, 16 and 17. The interesting points to be noted are: (1) the displacement does not vary in a consistent way with interply layer modulus, or with damping, for the four different excitation modes. This makes it difficult to generalize and, therefore, each case needs to be evaluated individually. (2) Considerable shear and through-the-thickness motions occur in the third excitation mode (fig. 16) at interply degradations approaching the equivalent of a delamination condition. (3) Practically all the motion is through the thickness in the fourth mode excitation at interply degradations approaching the equivalent of a delamination condition. Both points (2) and (3) have significant implications for fatigue delamination growth in the shearing and/or opening modes in laminates as well as in adhesively bonded joints.

The import conclusions from the above discussion are: (1) the interply layer damping effects are negligible in the range of interply layer modulus 0.1 million psi and greater; (2) interply layer damping effects are very sig. nificant as the interply degradation approaches the equivalent delamination condition; and (3) considerable shearing and through-the thickness motions occur as the interply degradation approaches the equivalent of a delamination condition especialiy near free edges. 
Impact

The interply degradation effects on the impact response of a composite beam are shown in figure 18 in terms of the maximum displacement versus time for 3 different values of interply layer modulus. Damping was assumed to vary with interply modulus and shear stress. The forcing function simulating the impact is also shown in this figure. The impact response is a complex combination of various vibration mode shapes which appear to participate with different relative proportions as time increases. The displacement is relatively small at early times, especially for the cases where the interply layer modulus is 100000 psi or greater. However, the displacement is considerable for interply modulus of $10000 \mathrm{psi}$. This implies that the impact displacement increases rapidly as the interply degradation approaches delamination.

Three important conclusions follow: (1) The interply degradation effects result in a complex impact response for composite beams most likely requiring direct time integration for evaluation. (2) Interply degradations with modulus 100000 psi or greater have negligible effects on the impact response at early times. However, this may not be the case as time increases. (3) Interply layer degradations approaching the equivalent of a delamination condition will cause large bending displacements, thus leading to comparably large energy absorption. The last conclusion applies equally well to composite beams with relatively soft interply layers.

\section{SUMMARY OF RESULTS}

The results of an investigation to evaluate the effects of progressive interply layer degradation on composite structural response (using a simply supported beam) are summarized below.

(1) The effects of progressive degradation of interply layers on structural response are evaluated using finite element analysis.

(2) Interply degradation effects on all types of structural response investigated herein are negligible if the effective interply layer modulus does not degrade below 200000 psi.

(3) The plies in the composite start responding as if they were individual beams when the interpiy modulus degrades below about 100000 psi and behave as if they were individual beams as the interply degradation approaches the equivalent of a delaminated condition.

(4) Interply degradation has negligible effects on the bucking mode even when the degradation approaches delamination ( $E$ less than $10000 \mathrm{ps} i$ ).

(5) Interply degradation approaching delamination excites substantial through-the-thickness modes. 
(6) Interpiy degradation has negligible effects on forced vibration response when the interply modulus does not degrade below 100000 psi. However, it has significant effect as the degradation approaches delamination (E less than 10000 psi).

(7) Interply degradation has noticeable effects on impact response when the interply modulus degrades below 100000 psi, and very significant effects as the modulus degradation approaches the delamination range.

(8) Considerable interply degradation must occur (interply layer modulus degradation approaching delamination) in order to appreciably affect/degrade the composite structural integrity as determined by (1) bending, (2) buckling, (3) free vibration, (4) forced excitation, and (5) impact. 


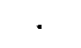




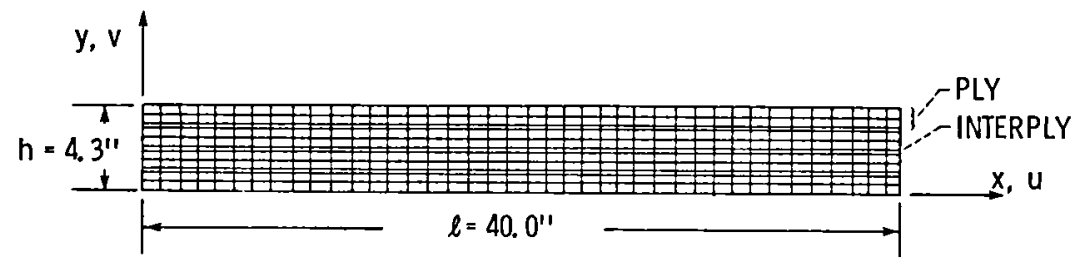

$$
\begin{array}{l|l}
\text { ELEMENTS: } & 440 \\
\text { NODES } & 492 \\
\text { ELEMENT } & \text { PLY: } 2 / 1 \\
\text { ASPECT RATIO } & \text { INTERPLY: } 10 / 1 \\
\text { SUPPORT: } & x=y=0: \quad \text { u, } v=0 \\
& x=\ell, y=0: v=0 \\
\text { PLY: } & E_{x}=20 \times 10^{6} p s i: \text { Ey }=2 \times 10^{6} \mathrm{psi} ; G=0.8 \times 10^{6} \mathrm{psi} \\
\text { INTERPLY: } & 1000 \mathrm{psi} \leq \mathrm{E} \leq 1 \times 10^{6} \mathrm{psi}
\end{array}
$$

Figure 1. - Finite element model and composite.

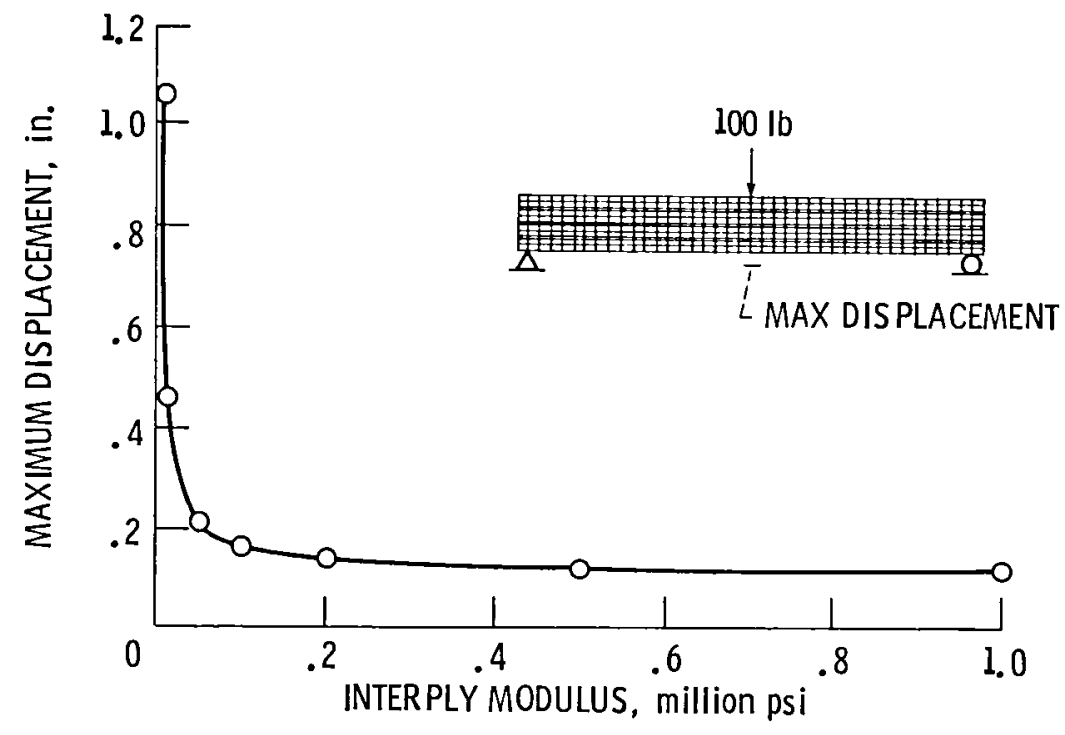

Figure 2. - Interply degradation effects on maximum bending displacement. 


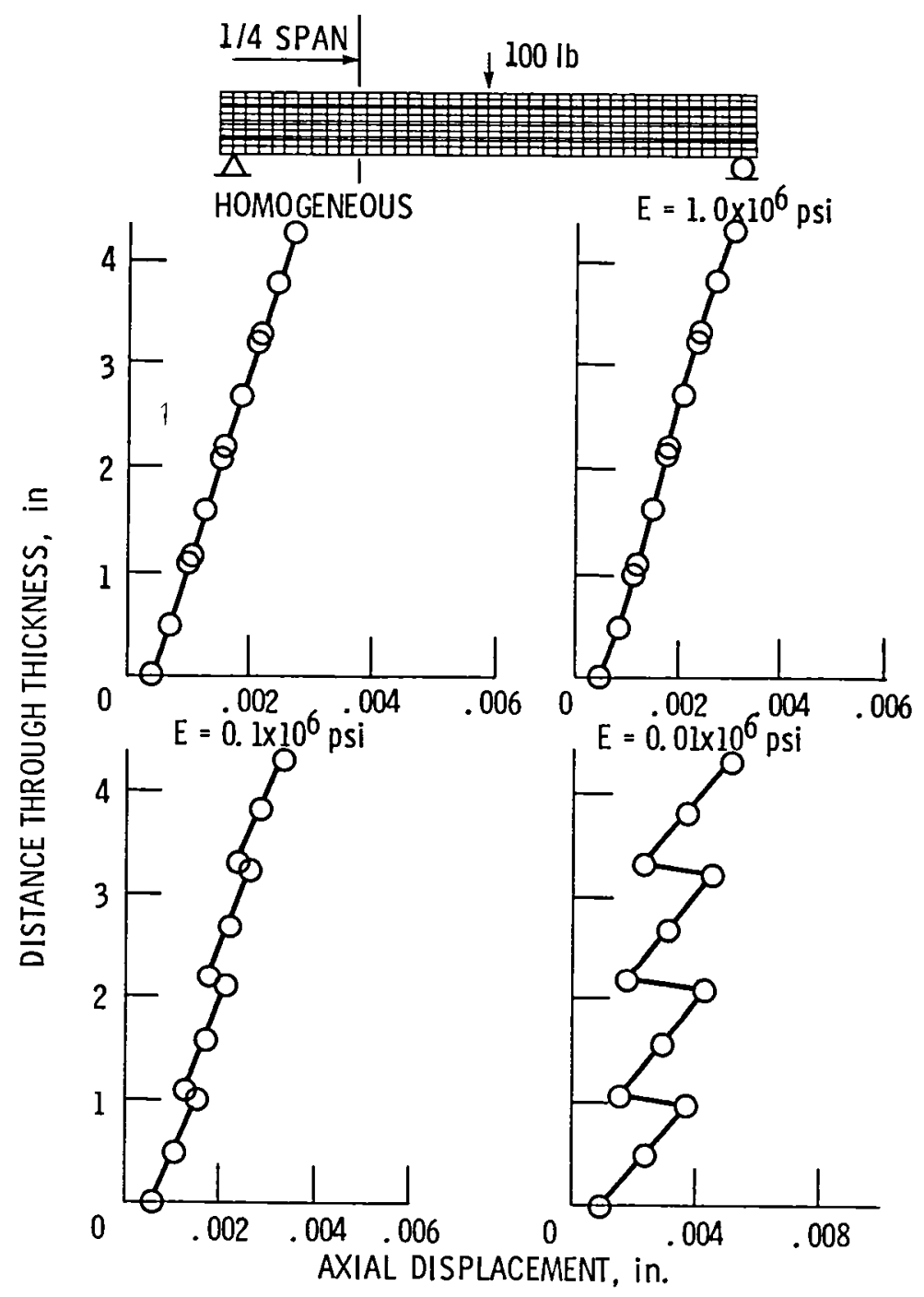

Figure 3. - Interply degradation effects on axial displacement through a section at the quarter span. 


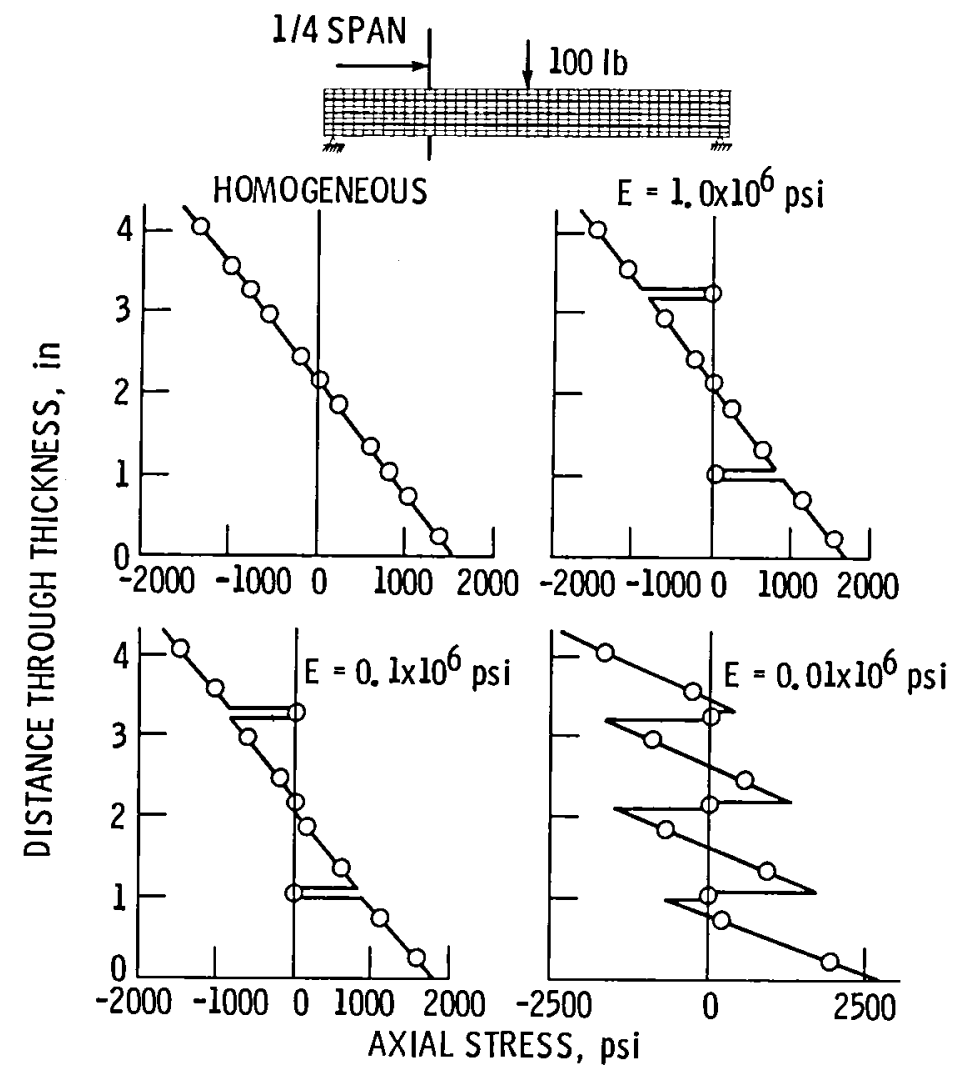

Figure 4. - Interoly degradation effects on axial stress through a section at quarter span. 


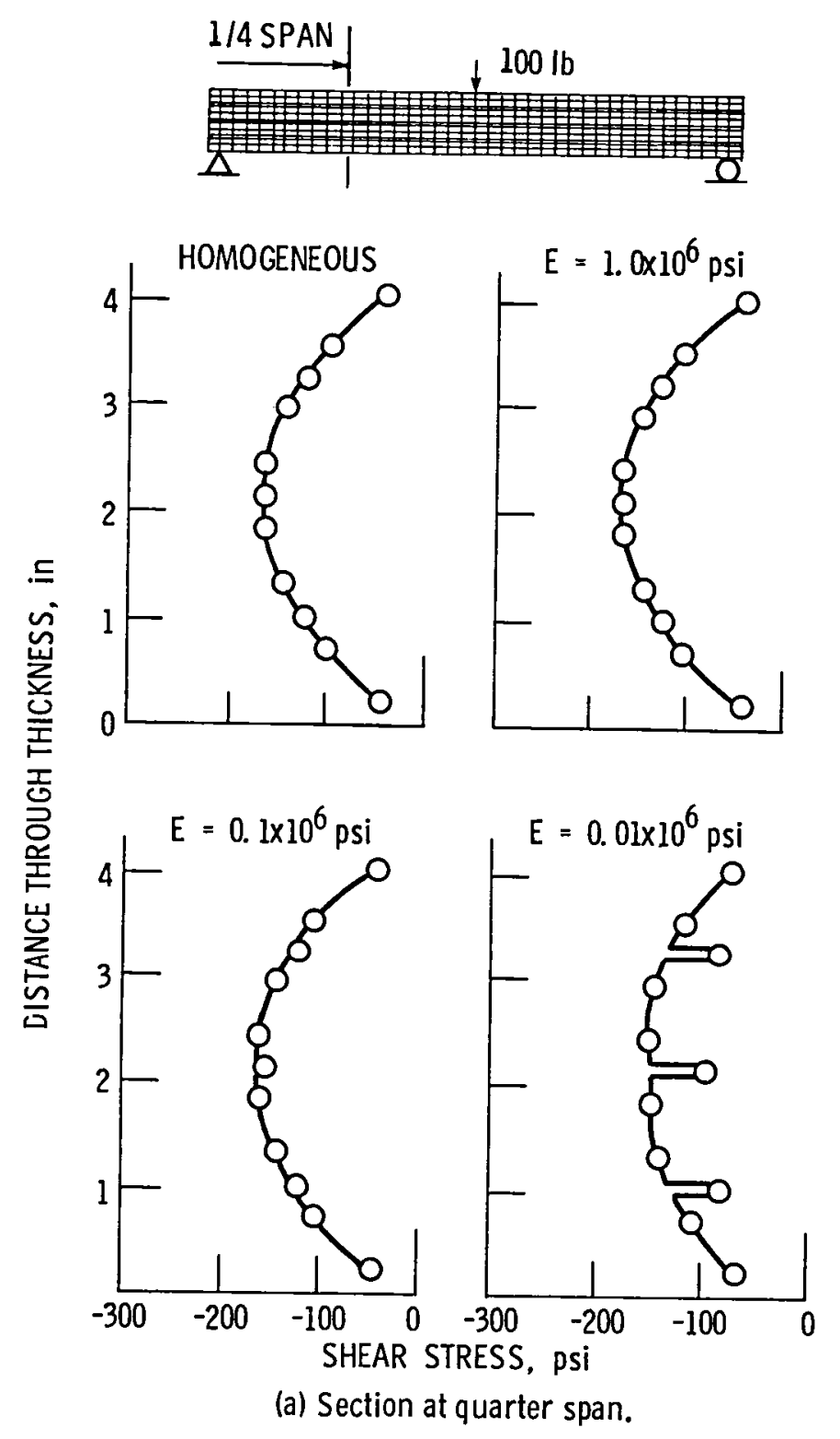

Figure 5. - Interply degradation effects on shear stress. 


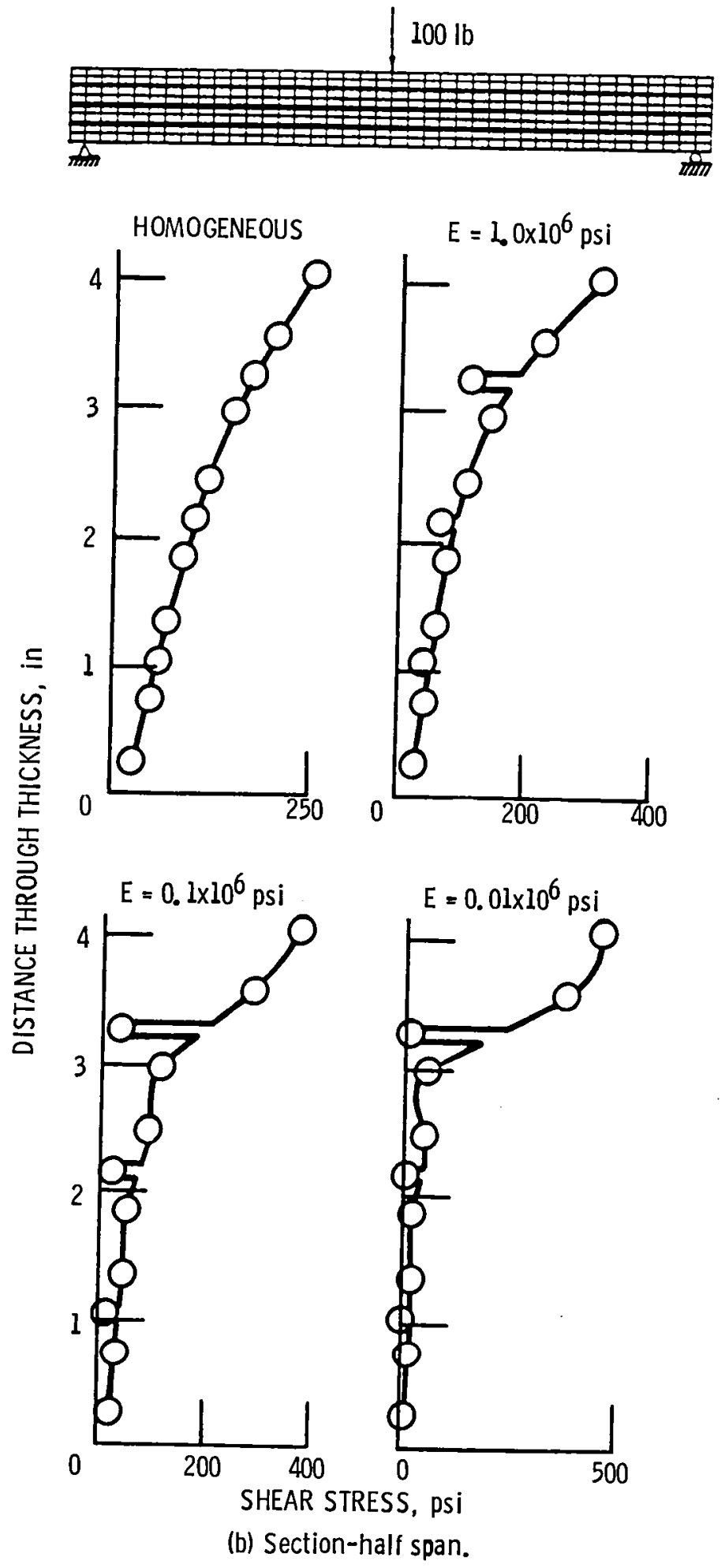

Figure 5. - Concluded. 


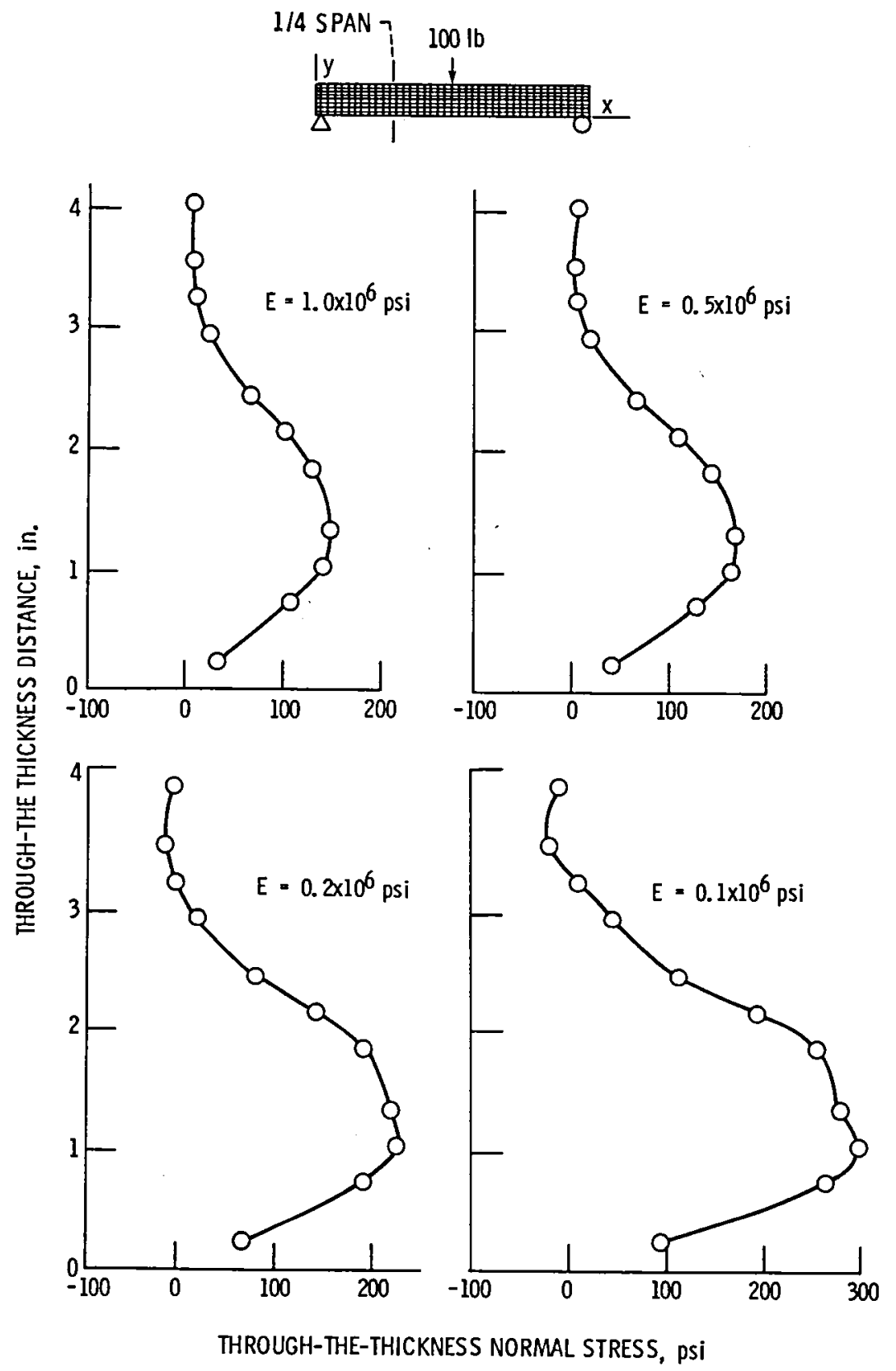

Figure 6. - Interply layer progressive degradation effects on through-thethickness normal stress at $1 / 4$ span. 


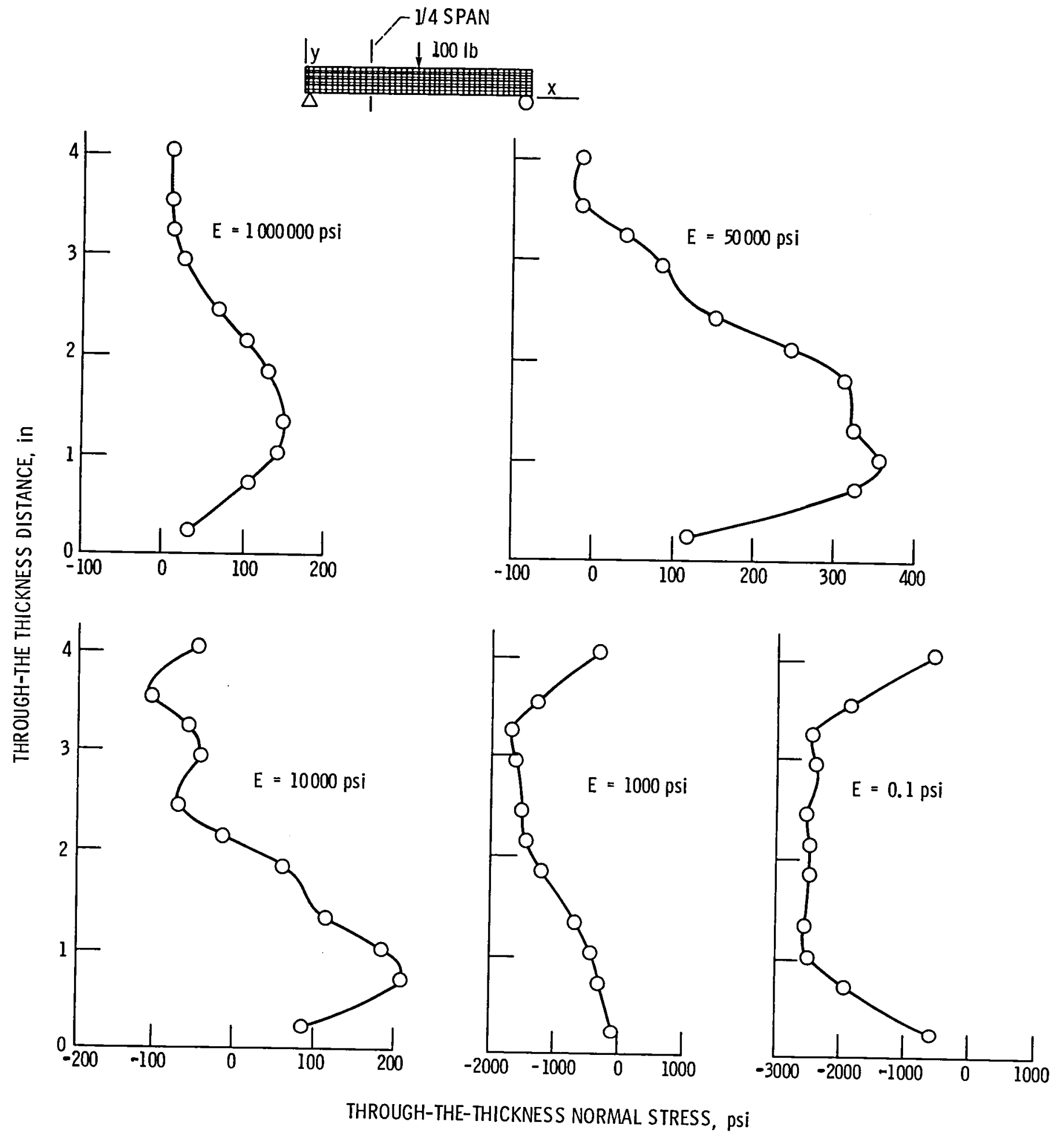

Figure 6. - Concluded. 


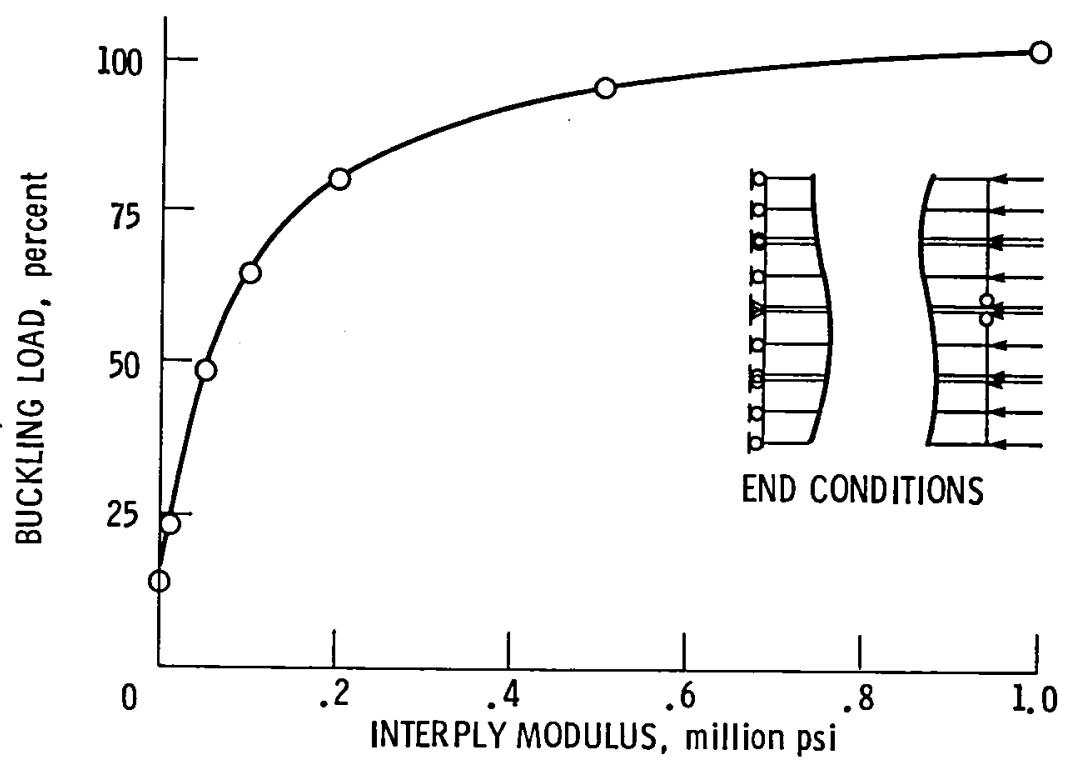

Figure 7. - Interply degradation effects on buckling load.
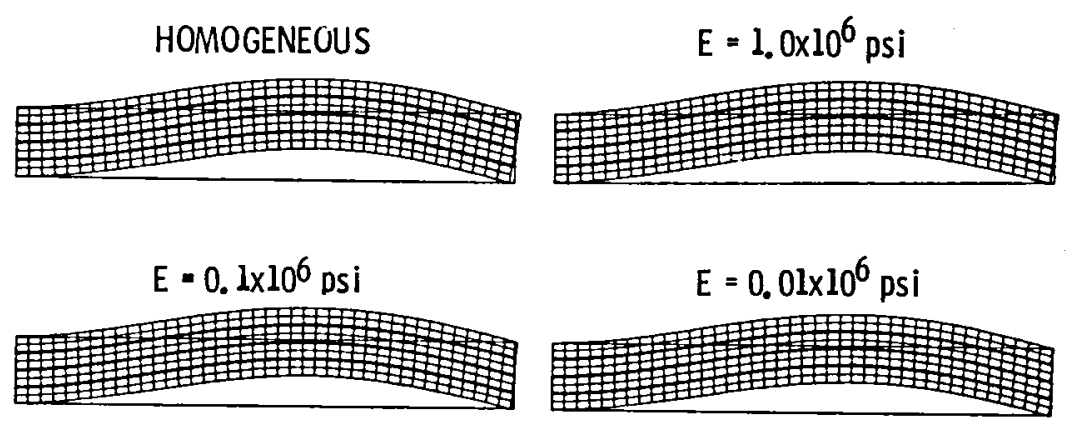

Figure 8. - Interply degradation effects on buckling modes. 


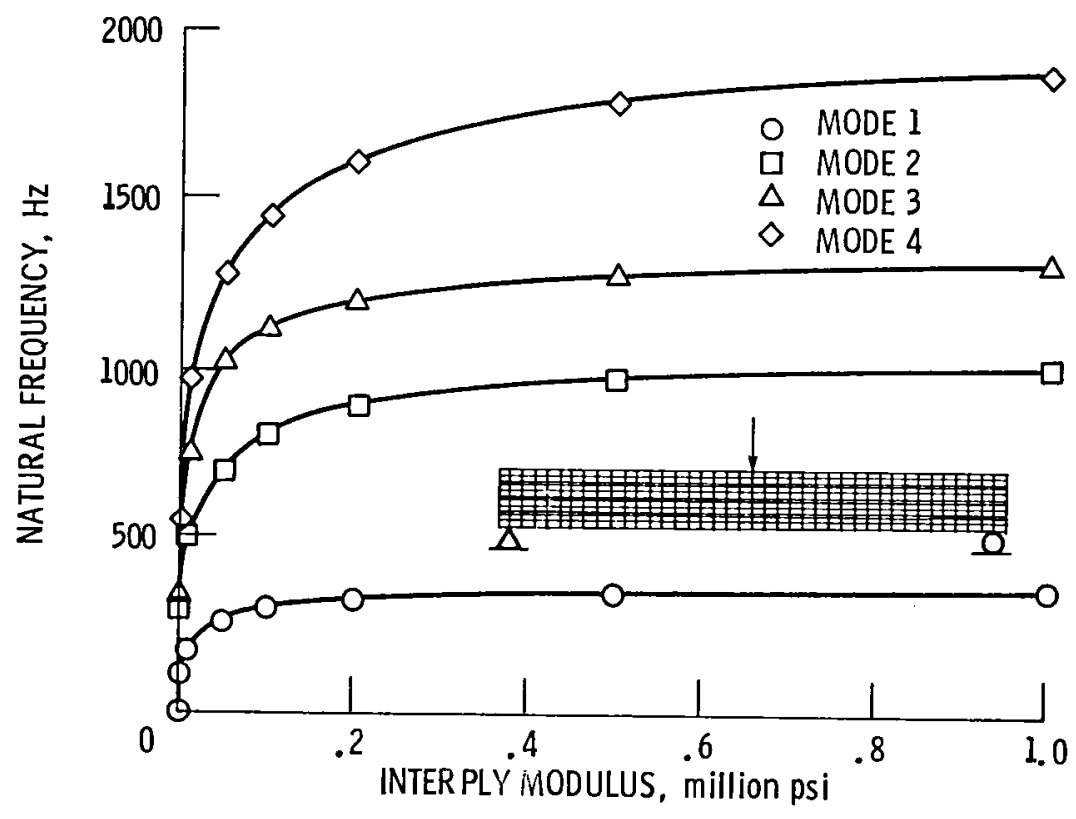

Figure 9. - Interply degradation effects on vibration frequencies.
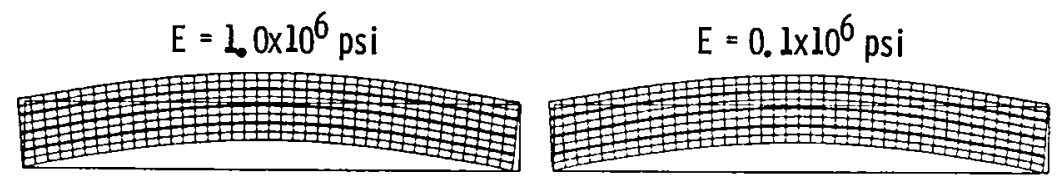

$E=0.01 \times 10^{6} \mathrm{psi}$ $E=0.001 \times 10^{6} \mathrm{psi}$
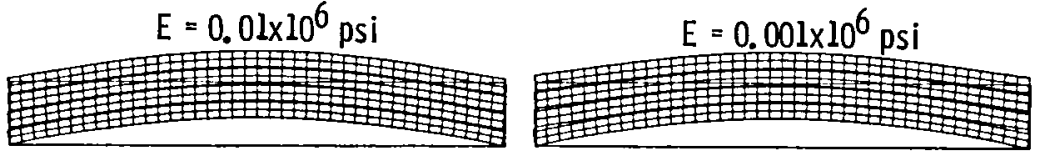

Figure 10 - Interply degradation effects on the lst vibration mode. 

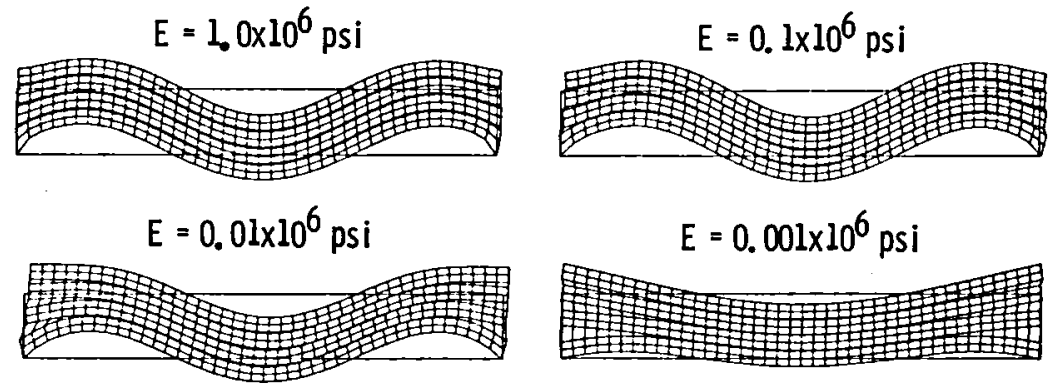

Figure 1l. - Interply degradation effects on the 4th vibration mode.

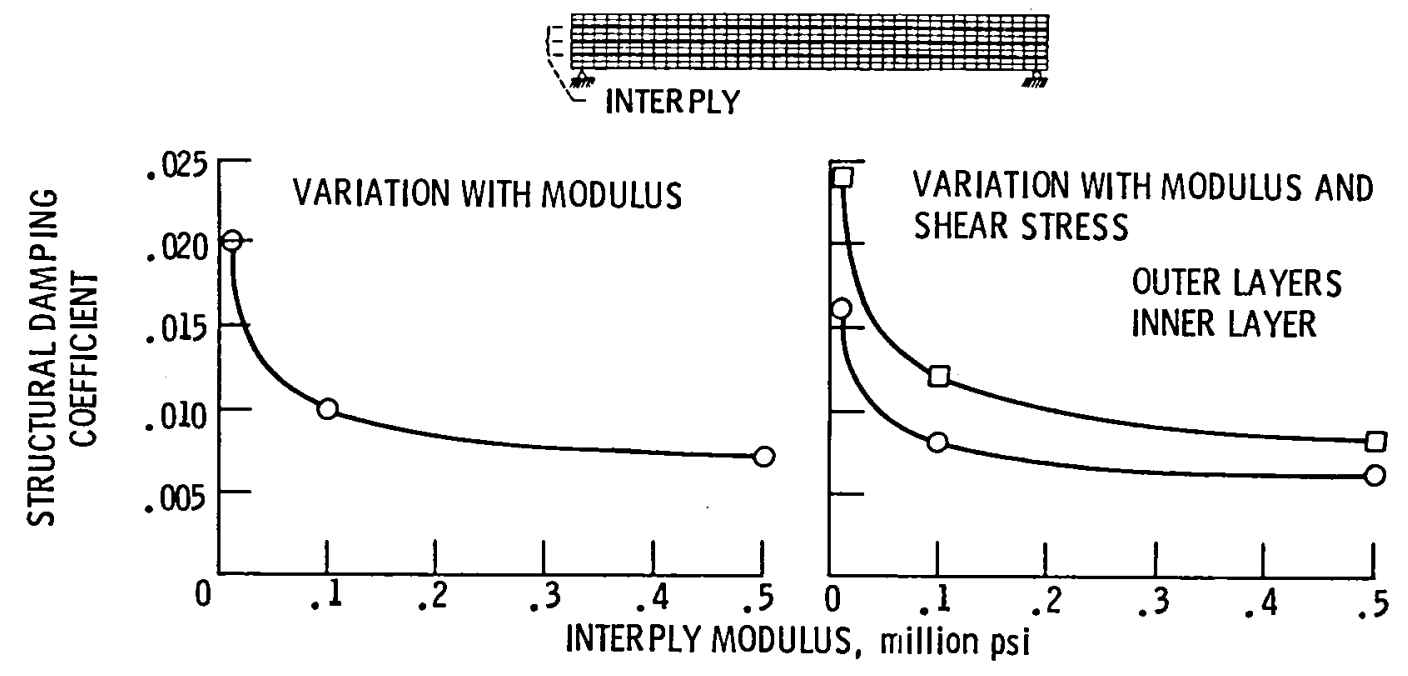

Figure 12. - Damoing coefficients for forced vibration response. 


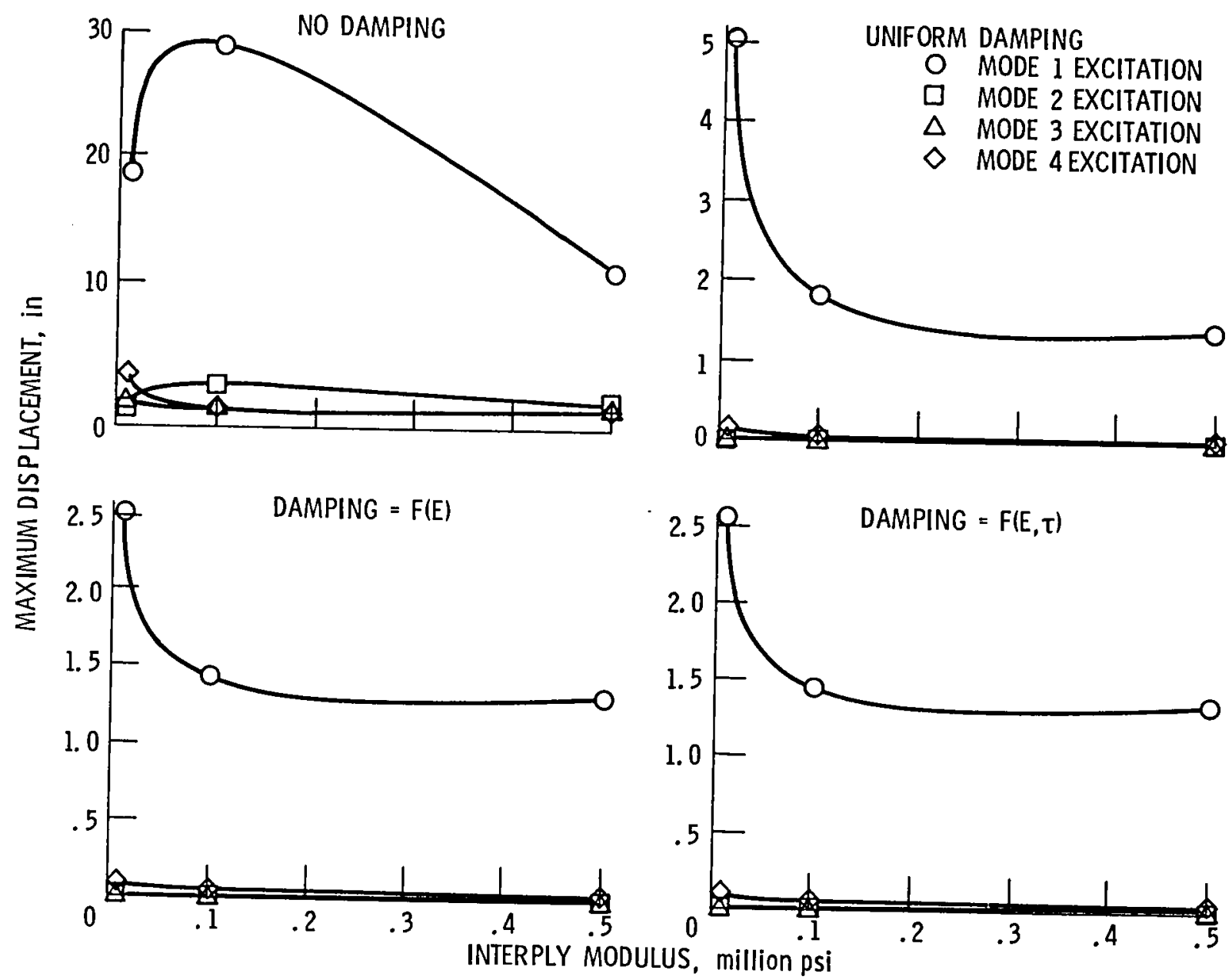

Figure 13. - Interply degradation effects on forced vibration response maximum displacement. 


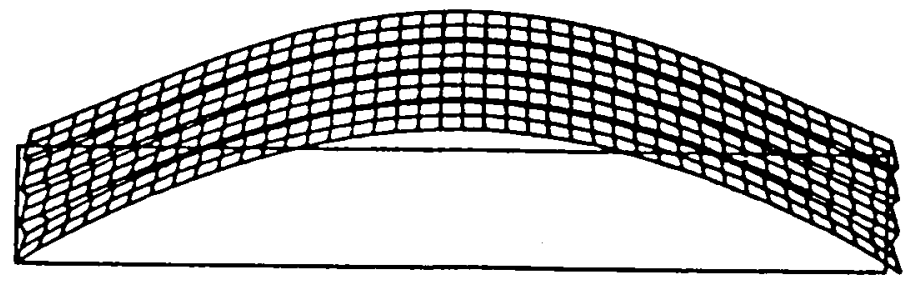

(1X; UNIFORM DAMPING $=0.01 ; \mathrm{E}=10000 \mathrm{psi})$
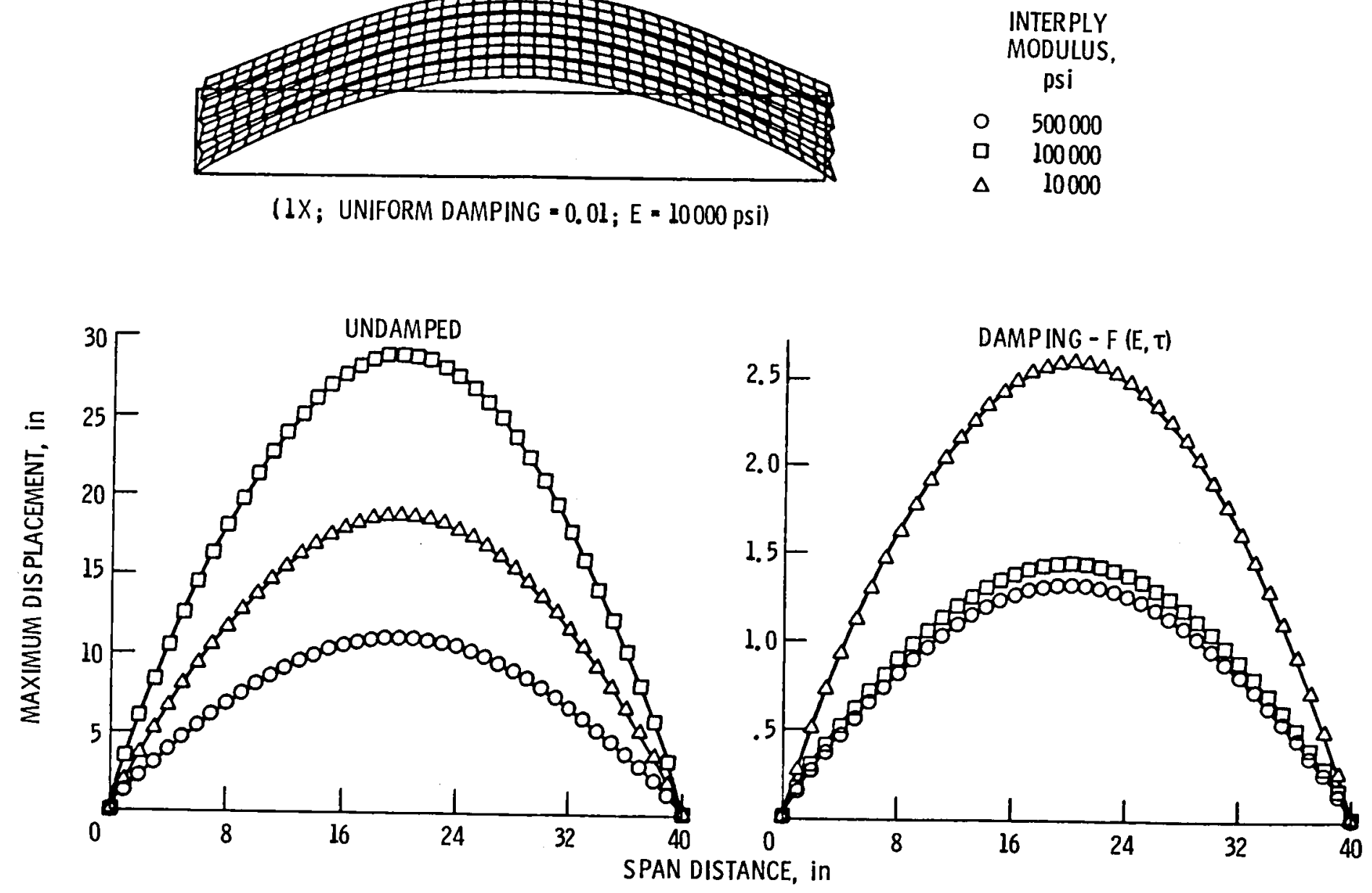

Figure 14. - Interoly degradation effects on forced vibration lst mode response. 


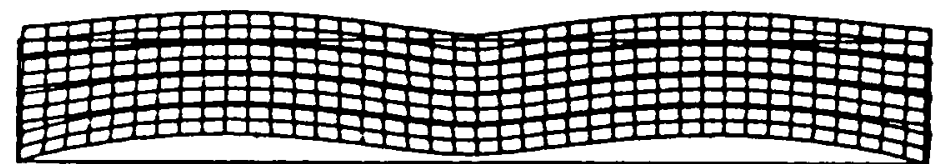

(50X; UNIFORM DAMPING $=0.01 ; \mathrm{E}=10000 \mathrm{psi})$
INTERPLY

MODULUS,

psi

500000

100000

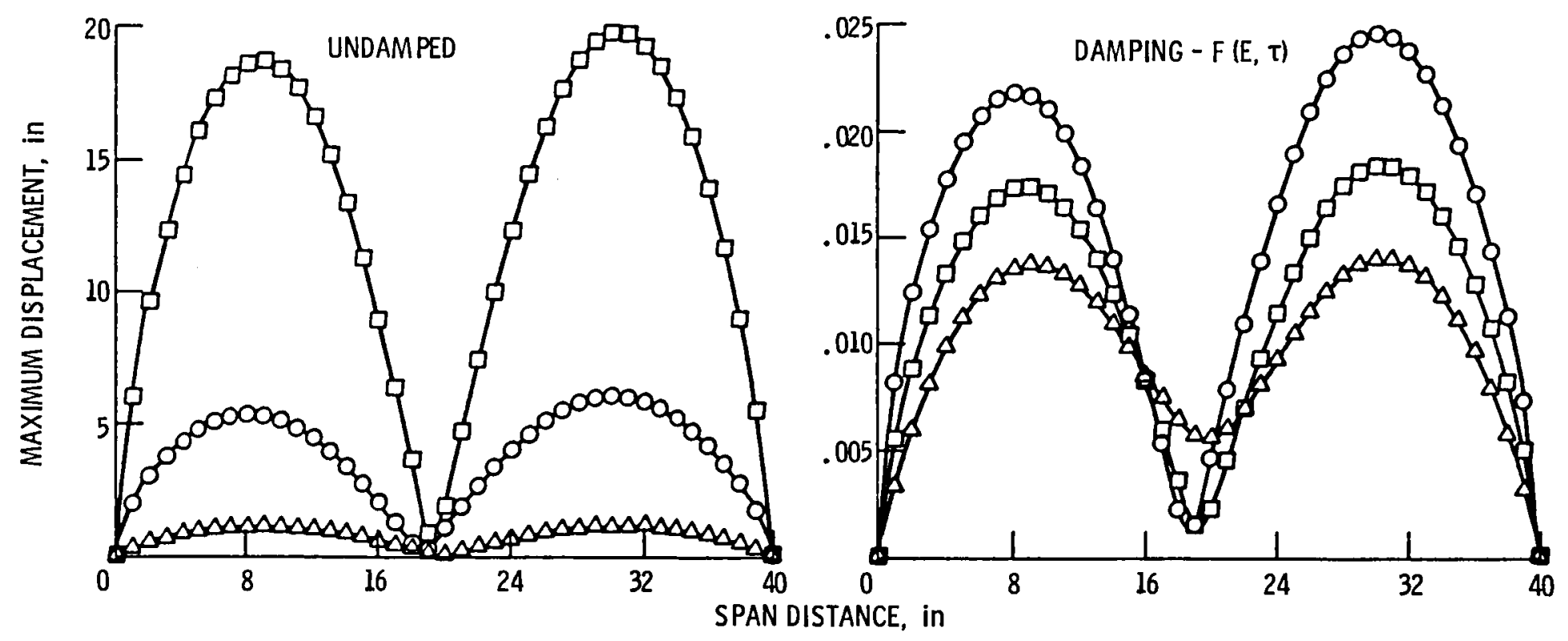

Figure 15. - Interply degradation effects on forced vibration 2 nd mode response. 


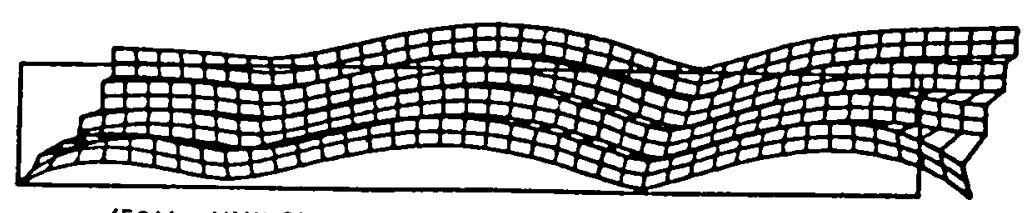

(50X; UNIFORM DAMPING = 0.01; E = 10000 psi)
INTERPLY

MODULUS,

psi

$\begin{array}{lr}\circ & 500000 \\ \square & 100000 \\ \Delta & 10000\end{array}$
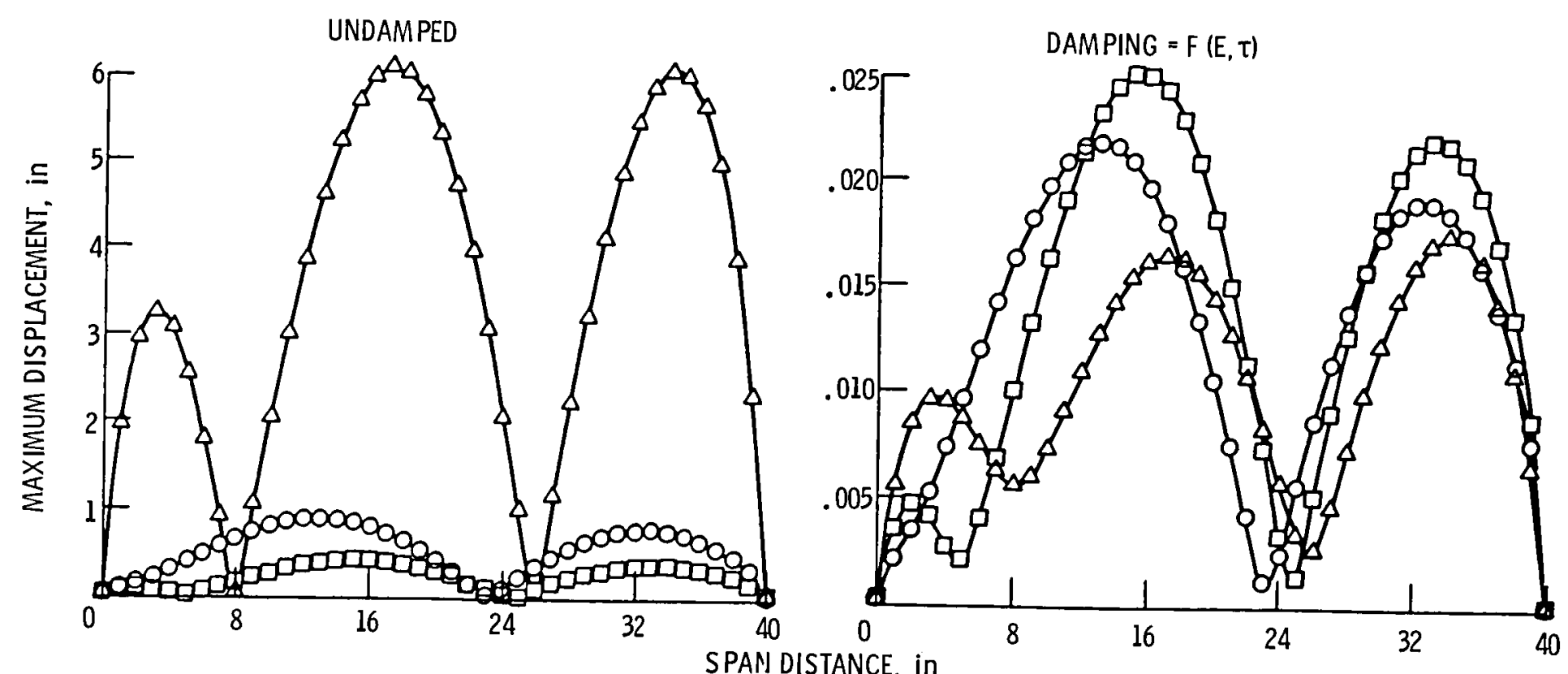

Figure 16. - Internly degradation effects on forced vibration 3rd mode response. 


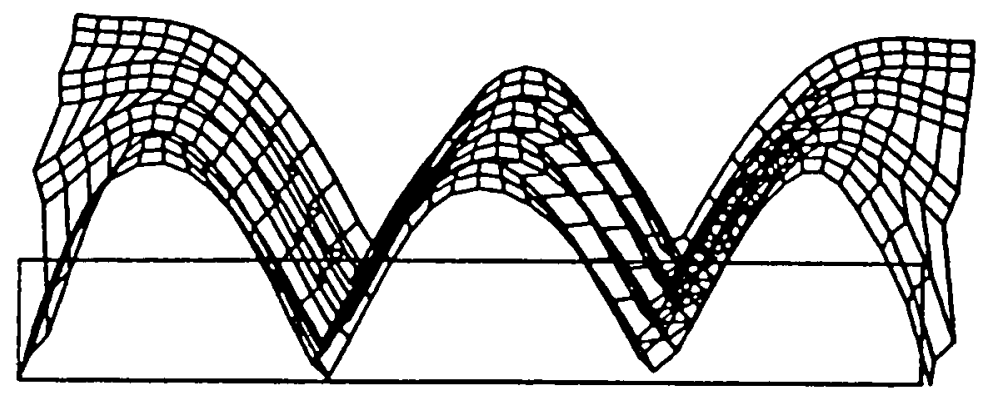

(50X; UNIFORM DAMPING $=0.01 ; E=10000 \mathrm{psi})$
INTER PLY

psi

$\begin{array}{ll}\circ & 500000 \\ 0 & 100000\end{array}$

$\triangle 10000$
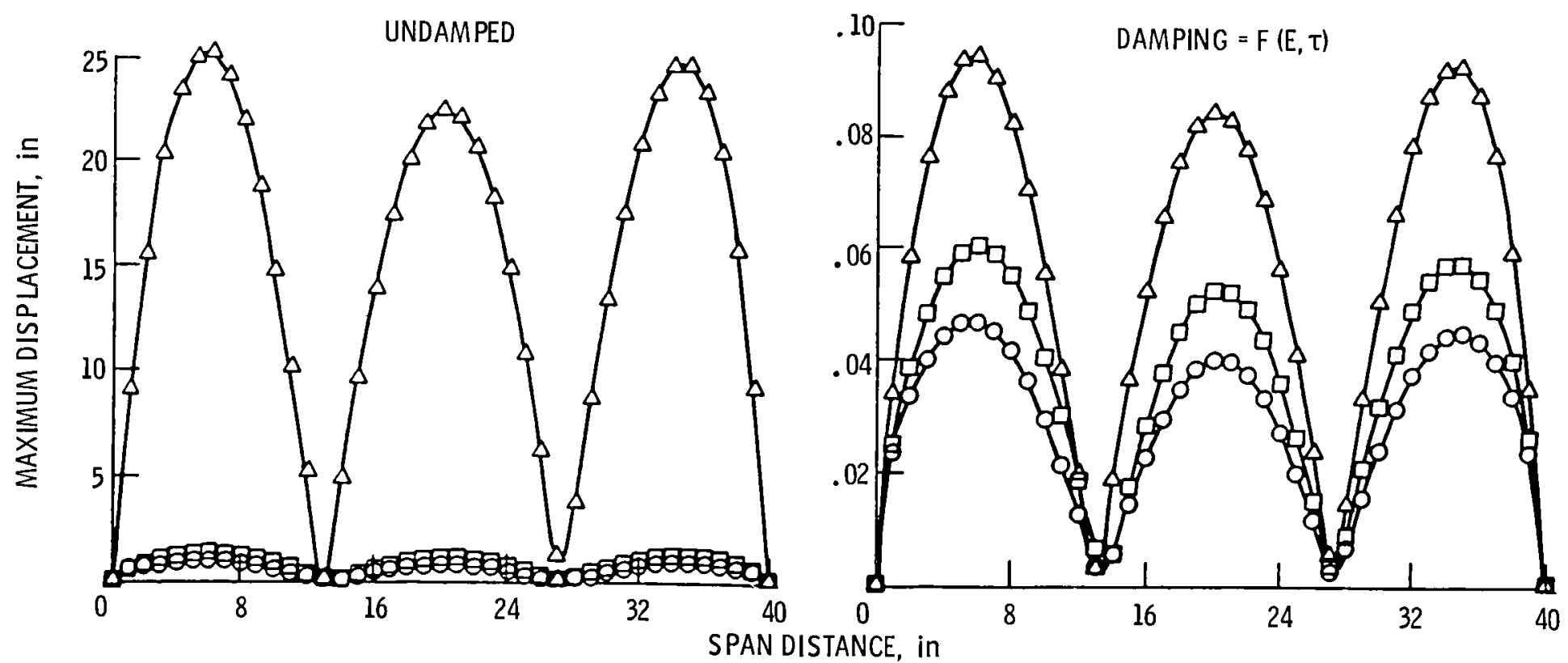

Figure 17. - Interply degradation effects on forced vibration 4th mode response. 
MIDSPAN DISPLACEMENT
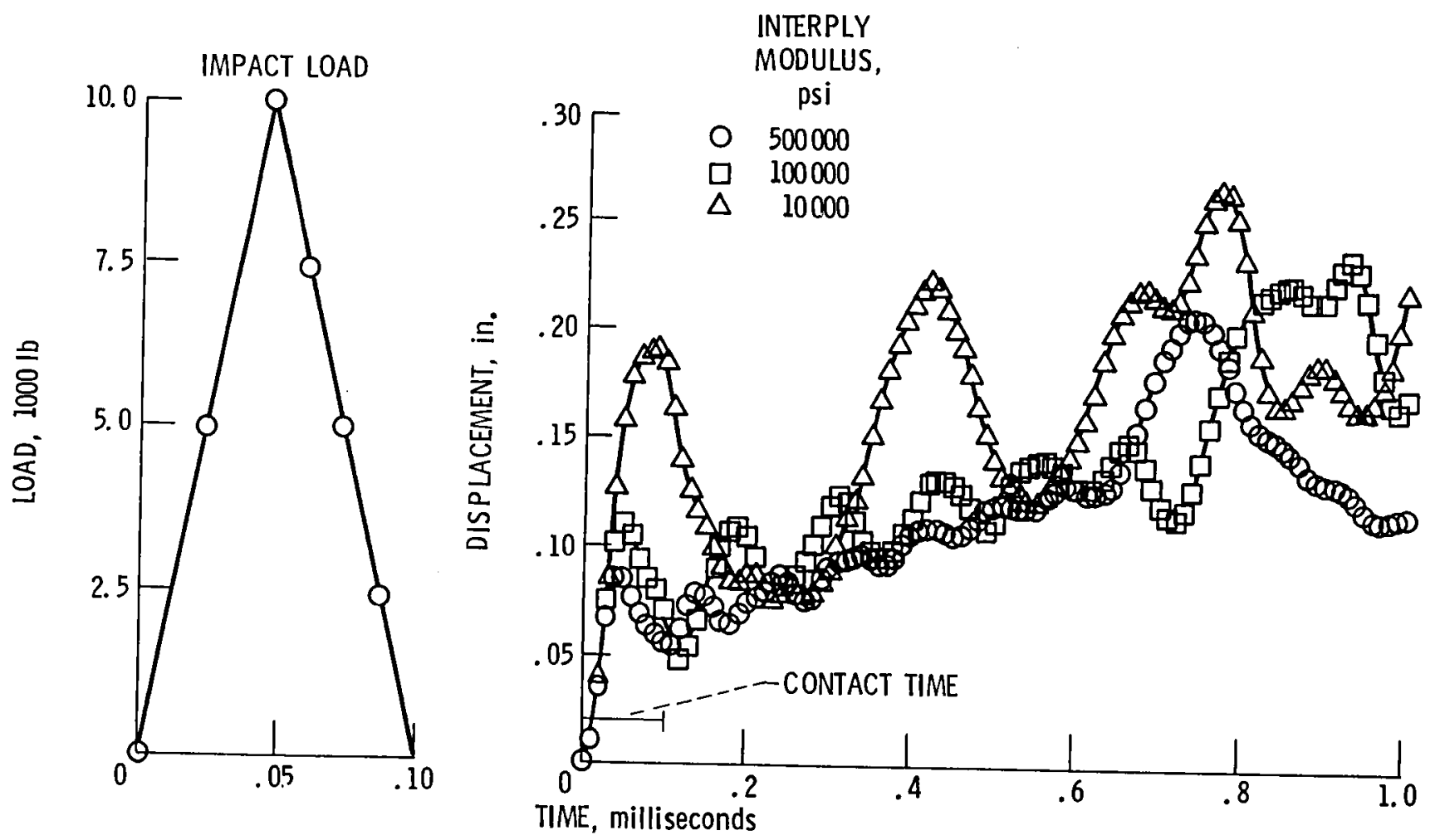

Figure 18. - Interply degradation effects on impact response. 



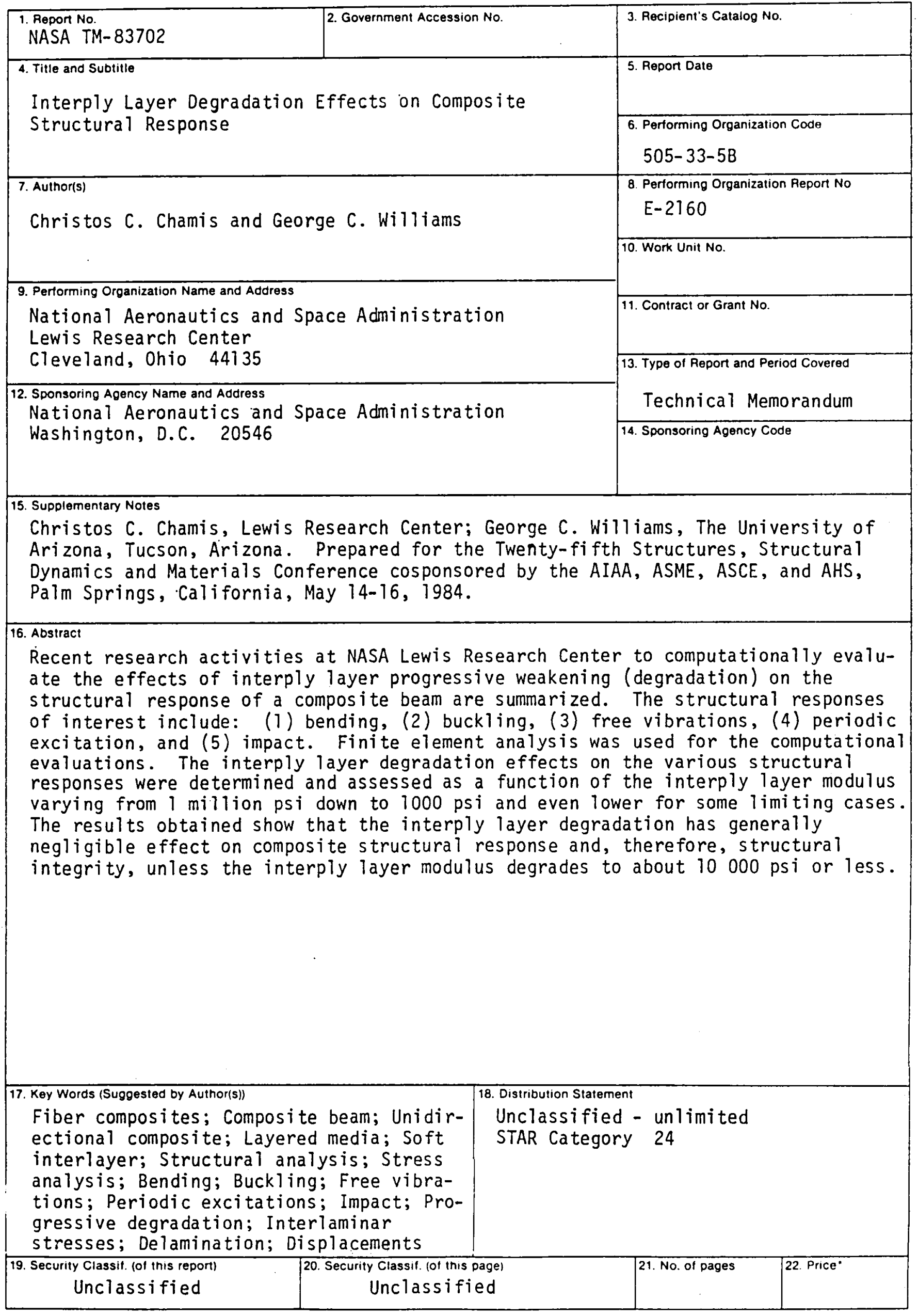


, 
National Aeronautics and Space Administration

Washington, D.C.

20546

Official Business

Penaliv for Private Use, $\mathbf{5 3 0 0}$
SPECIAL FOUATH CLASSMAIL

BOOK

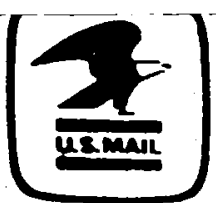

Postage and Foes Paid

National Aeronoutics and

Space Administration

NASA-451 